\title{
Early stage evaluation of colon cancer using tungsten disulfide quantum dots and bacteriophage nano-biocomposite as an efficient electrochemical platform
}

\author{
Ramin Pourakbari ${ }^{1,2,3}$, Mehdi Yousefi ${ }^{3 *}$, Balal Khalilzadeh ${ }^{2 *}$ (D) Mahsa Haddad Irani-nezhad ${ }^{4}$, Alireza Khataee ${ }^{4,5}$, \\ Leili Aghebati-Maleki ${ }^{6}$, Alireza Soleimanian ${ }^{7}$, Amin Kamrani ${ }^{2}$, Forough Chakari-Khiavi ${ }^{7}$, Rozita Abolhasan², \\ Morteza Motallebnezhad ${ }^{8}$, Farhad Jadidi-Niaragh ${ }^{9}$, Bahman Yousefi ${ }^{10}$, Hossein Samadi Kafil $^{10}$, \\ Mohammad Hojjat-Farsangi ${ }^{11}$ and Mohammad-Reza Rashidi ${ }^{7}$
}

\begin{abstract}
${ }^{*}$ Correspondence:
Yousefime@tbzmed.ac.ir; khalilzadehb@tbzmed.ac.ir; balalkhalilzadeh@gmail.com 2 Stem Cell Research Center (SCRC), Tabriz University of Medical Sciences,

51664-14766 Tabriz, Iran

${ }^{3}$ Department

of Immunology, School of Medicine, Tabriz University of Medical Sciences, Tabriz Iran

Full list of author information is available at the end of the article
\end{abstract}

\begin{abstract}
Background: Recently, biosensors have become popular analytical tools for small analytes due to their high sensitivity and wide analytical range. In the present work, development of a novel biosensing method based on tungsten disulfide quantum dots (WS ${ }_{2}$ QDs)-Au for rapidly and selectively detecting c-Met protein is introduced. As a proof of concept, M13 bacteriophage-based biosensors were used for the electrochemical detection of c-Met protein as a colon cancer biomarker.

Method: The M13 bacteriophage (virus), as the biorecognition element, was immobilized on glassy carbon electrodes which were modified by WS, QDs-functionalized gold nanoparticles. The stepwise presence of the WS 2 QDs, gold nanoparticles, and immobilized phage on glassy carbon electrodes were confirmed by scanning electron microscope (SEM) and square wave voltammetry (SWV) technique.

Results: The designed biosensor was applied to measure the amount of c-Met protein in standard solutions, and consequently the desirable detection limit of 1 pg was obtained. Finally, as a proof of concept, the developed platform was used for the evaluation of c-Met protein in serum samples of colon cancer-suffering patients and the results were compared with the results of the common Elisa kit.

Conclusions: As an interesting part of this study, some concentrations of the c-Met protein in colon cancer serum samples which could not be determined by Elisa, were easily analyzed by the developed bioassay system. The developed bioassay system has great potential to application in biomedical laboratories.
\end{abstract}

Keywords: Electrochemical, Biosensor, Cancer marker, Phage, Gold nano-layer, WS 2 QDs

(c) The Author(s) 2022. Open Access This article is licensed under a Creative Commons Attribution 4.0 International License, which permits use, sharing, adaptation, distribution and reproduction in any medium or format, as long as you give appropriate credit to the original author(s) and the source, provide a link to the Creative Commons licence, and indicate if changes were made. The images or other third party material in this article are included in the article's Creative Commons licence, unless indicated otherwise in a credit line to the material. If material is not included in the article's Creative Commons licence and your intended use is not permitted by statutory regulation or exceeds the permitted use, you will need to obtain permission directly from the copyright holder. To view a copy of this licence, visit http:// creativecommons.org/licenses/by/4.0/. The Creative Commons Public Domain Dedication waiver (http://creativecommons.org/publi cdomain/zero/1.0/) applies to the data made available in this article, unless otherwise stated in a credit line to the data. 


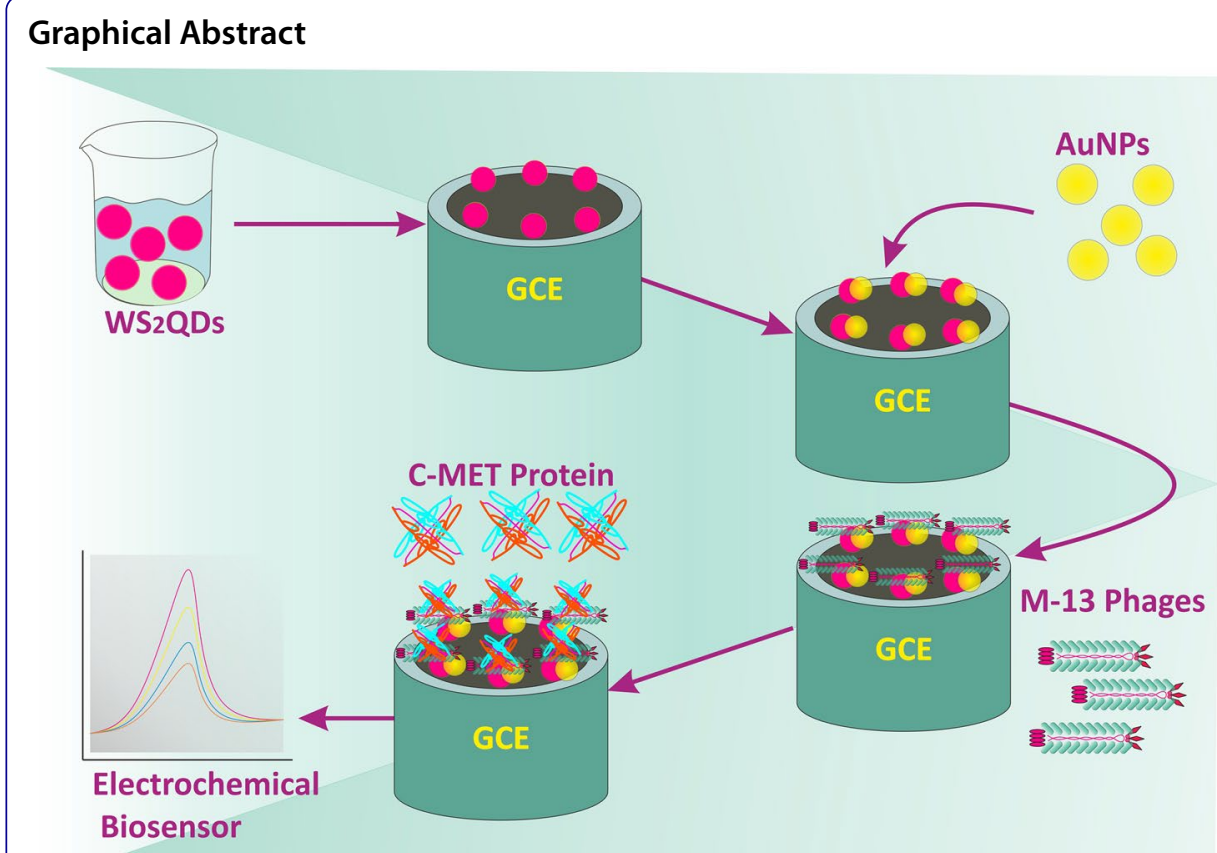

\section{Introduction}

According to reports of the WHO, approximately 9 million people died in 2015 from a variety of cancers (Pourakbari et al. 2020). In recent decades, the rates of death from cancer malignancies have sharply increased. However, by improving the early stage detection processes, the cancer mortality rates could be reduced significantly (Fitzgerald 2020). The most routinely employed methods for colon cancer diagnosis, including colonoscopy, fecal immunochemical test (FIT) (Gupta et al. 2013), and sigmoidoscopy (Winawer et al. 1993), are based on tissue sampling, imaging, etc. (Rathore et al. 2013). These approaches have several disadvantages, such as invasive nature, time-consuming processes, high cost, and especially insufficient sensitivity for early detection of malignancies (Grossman et al. 1989). On the other hand, the application of biosensors (as new detection devices), and their combination with advanced nanomaterials (Jaymand 2011; Jafarizad et al. 2018) and biomaterials (Massoumi et al. 2020) for early stage and precise diagnosis of cancers has increased nowadays in the biomedical research areas (Pourakbari et al. 2019; Isildak et al. 2020; Khalilzadeh et al. 2019, 2017). Biosensors offer some benefits including; ultrahigh sensitivity, desirable selectivity, cost-effectiveness, real-time monitoring, and fast response time. These features make biosensors potent, on-desk, and ready-to-use devices for clinical analyses, which also have a robust capacity for both in vitro and in vivo applications for routine clinical laboratory tests (Soleymani and Li 2017; Hasanzadeh et al. 2018; Manzoori et al. 2012; Soleymani et al. 2017). The lack of sufficient sensitivity to low concentrations of cancer biomarkers in unprocessed blood or serum in the past decades has forced the development of new strategies, such as the merging of nanotechnology and electrochemical biosensors that can partially overcome this problem. The upgrading of electrochemical nano-biosensors seems to be a problem-solving 
approach with regards to sensitivity, speed, and selectivity (Wang et al. 2013). In addition, electrochemical sensors and biosensors have significant role in biomedical and pharmaceutical analysis (Saghatforoush et al. 2009; Khalilzadeh et al. 2011, 2015).

Quantum dots are a subcategory of semiconductors, in which, they have been used as electrochemical modifiers for improving the sensitivity of sensors and specially biosensors (Bera et al. 2010; Jalili and Khataee 2019). Tungsten (W), as an electroactive metal, and its combination with sulfide compounds make an advanced material with high surface area and acceptable electrical conductivity for application as modifier in electrochemical-based biosensors (Pumera and Loo 2014). The electrical conductivity feature of $\mathrm{WS}_{2}$ could be further improved by merging $\mathrm{WS}_{2}$ with conductive compounds, such as metallic nanoparticles, such as gold, silver, and platinum via onestep or sequential electrodeposition processes (Polyakov et al. 2014; Khataee et al. 2018). In this study, we applied AuNPs, which were used as a bi-proposed layer. First, they were used for improving the electrical conductivity of the developed platform, and second, they were applied for bioconjugation of bioreceptors on the designed electrochemical platform.

Some receptor tyrosine kinases (RTKs) are proto-oncogenes that are involved in the activation process of downstream signaling molecules, which play a part in cell proliferation, migration, and survival (Safaie Qamsari et al. 2017). Among the most important receptors of the RTKs are c-Kit (also known as tyrosine-protein kinase KIT), Ephrin receptor, Platelet-derived growth factor (PDGF), fms-like tyrosine kinase 3 (Flt3; which in fact belongs to the receptor tyrosine kinase class III), and tyrosine-protein kinase Met (c-Met) (Ma et al. 2003). Binding of c-Met to its ligand, namely, the hepatocyte growth factor (HGF) receptor, initiates a chain of intracellular signaling pathways that interfere with the embryogenesis as well as the process of wound healing in normal cells. Nevertheless, the aberrant HGF/c-Met signaling in malignant cells, which is almost attributed to the mutations, overexpression, and amplification of the c-Met gene, results in the progression of the tumor through the stimulation of PI3K/AKT, MAPK/ERK, JAK/STAT, Wnt/ $\beta$-catenin, as well as some other signaling pathways (Birchmeier et al. 2003). Fundamental roles of the c-Met (mesenchymal epithelial transition factor) have been investigated in numerous researches involving the spreading and metastasis of many various malignancies in humans, such as pancreas, colon, stomach, breast, prostate, bones, liver, and ovary (Ma et al. 2003).

Recently, some unique features, such as high specificity for target molecules, temperature stability, and easy production procedures, have led to the increased use of bacteriophages in various fields. The application of bacteriophages in biotechnology and biosensors has increased during the last decades (Gervais et al. 2007). Because of the declared top features of bacteriophages, we used these bioreceptors on $\mathrm{WS}_{2}$-AuNPs platform for the detection of c-Met protein.

In this project, $\mathrm{WS}_{2}$ QDs were cast-dried on the GCE, and then the AuNPs were electrochemically deposited on the modified electrode. Following, the c-Met bacteriophage, as the biorecognition element was immobilized on the modified electrode, and was finally applied for electrochemical evaluation of c-Met protein as a colon cancer biomarker. As far as we are aware, this is the first report on the application of nanocomposition of $\mathrm{WS}_{2} \mathrm{QDs}$, AuNPs, and bacteriophage for early stage evaluation of colon cancer. 


\section{Materials and methods \\ Materials}

Gold (III) chloride trihydrate $\left(\mathrm{HAuCl}_{4}, 99.9 \%\right), \mathrm{KNO}_{3}, \mathrm{NaCl}, \mathrm{Na}_{2} \mathrm{HPO}_{4}, \mathrm{KH}_{2} \mathrm{PO}_{4}, \mathrm{KCl}$, $\mathrm{K}_{4}\left[\mathrm{Fe}(\mathrm{CN})_{6}\right] \cdot 3 \mathrm{H}_{2} \mathrm{O}$, ampicillin, and kanamycin were acquired from Sigma (St. Louis, MO). European bacteriological agar, extract of yeast, and Tryptone were obtained from Laboratorios Conda (Madrid, Spain). The c-Met protein, was bought from JPT (Berlin, Germany). Re-suspension of the peptide was performed in deionized water (at $0.2 \mathrm{mg} / \mathrm{mL}$ ), following which it was aliquoted and stored at $-20{ }^{\circ} \mathrm{C}$. $\mathrm{WS}_{2}$, dimethylformamide (DMF), ethanol, acetone, and $\mathrm{H}_{2} \mathrm{SO}_{4}$ (98\%) were supplied from Sinopharm Chemical Reagent Co. Ltd. (Shanghai, China).

\section{Apparatus and procedures}

Autolab potentiostat/galvanostat was utilized to perform electrochemical measurements including electrochemical impedance spectroscopy (EIS), differential pulse voltammetry (DPV), square wave voltammetry (SWV), and cyclic voltammetry (CV), for all of which the NOVA 1.8 software was used for data processing. Shimadzu $8101 \mathrm{M}$ FTIR spectrophotometer (Shimadzu, Kyoto, Japan) was employed to perform Fourier transform infrared (FTIR) experiments. Preparation of the FTIR discs was performed by grinding appropriate sample contents with KBr salt. A VEGA TESCAN (Czech Republic) instrument was utilized to take the scanning electron microscopy (SEM) images illustrating the stepwise modifications on glassy carbon electrode (GCE). Initially, exposure of the samples to the electron bombardment with gold atoms was performed under vacuum condition, and then the samples were moved to SEM chamber for taking the images.

The absorbance was measured with a spectrophotometer (Shimadzu UV-2550, Kyto, Japan), and fluorescence intensity was analyzed by the spectrofluorophotometer (Shimadzu RF-5301PC, Kyoto, Japan).

\section{Preparation of $\mathrm{WS}_{\mathbf{2}}$ QDs and AuNPs}

To this end, $1 \mathrm{~g}$ from tungsten disulfide powder was added to $100 \mathrm{~mL}$ of DMF, following which a solution was prepared and sonicated for $3 \mathrm{~h}$. Later, stirring of the collected suspension was performed in a sealed container for $6 \mathrm{~h}$ at $140{ }^{\circ} \mathrm{C}$. Proof of the successful production of the $\mathrm{WS}_{2}$ QDs was the observed yellow solution over the sediments. The supernatant was vaporized under vacuum condition at a specific temperature and the debris was re-suspended in double distillated water for further applications (Xu et al. 2015). Consequently, the yellowish tungsten sulfide nanosheets were obtained and confirmed by FTIR.

The AuNPs were prepared using in situ electrodeposition process (Chiang et al. 2019). In brief, a solution of $0.005 \mathrm{M}$ of $\mathrm{HAuCl}_{4}$ and $0.1 \mathrm{M}$ of $\mathrm{KCl}$ in deionized water was prepared. A portion of the obtained suspension was transferred onto the electrochemical cell and CV technique was applied for electrosynthesis process (the potential was swiped between -0.5 and $0 \mathrm{~V}$, scan rate $0.05 \mathrm{~V} / \mathrm{S}$, for 25 cycles). 


\section{Phage biopaning and amplification}

In this study, $500 \mathrm{~mL}$ of phagemid library was added to cultured media containing $200 \mathrm{~mL}$ of 2 XYT medium and ampicillin $(120 \mathrm{mg} / \mathrm{mL})$, by the time the optical density of the suspension at $600 \mathrm{~nm}$ (i.e., OD 600 ) achieved $\approx 0.4-0.5$. Then, approximately $5 \times 10^{11}$ plaque-forming units (PFU) from the helper phage M13K07 were supplemented to each milliliter of the bacterial culture, where they were incubated for $30 \mathrm{~min}$ at $37^{\circ} \mathrm{C}$, and later for another $30 \mathrm{~min}$ at $37^{\circ} \mathrm{C}$ on a shaker (at $100 \mathrm{rpm}$ ).

Consequently, the bacteria were centrifuged $\left(10 \mathrm{~min}, 4{ }^{\circ} \mathrm{C}\right.$, at $\left.4000 \mathrm{rpm}\right)$ and dispersed in $100 \mathrm{~mL}$ of fresh $2 \mathrm{XYT}$, which contained both ampicillin $(120 \mathrm{mg} / \mathrm{mL})$ and kanamycin $(50 \mathrm{mg} / \mathrm{mL})$. Next, incubation at $30{ }^{\circ} \mathrm{C}$ was performed for $16 \mathrm{~h}$ with shaking (200 rpm). Afterwards, purification of the phage was performed in line with the PEG/NaCl precipitation procedure (Qamsari et al. 2017).

\section{Electrode preparation steps and sequential modifications}

The GCE was polished with alumina powder followed by electrochemical cleaning, which was processed in $0.5 \mathrm{M} \mathrm{H}_{2} \mathrm{SO}_{4}$ using $\mathrm{CV}$ technique, where the potential range was $0.0-1.5 \mathrm{~V}$ versus $\mathrm{Ag} / \mathrm{AgCl}$ reference electrode at scan rate of $100 \mathrm{mVs}^{-1}$ for 10 cycles and finally dried with nitrogen stream.

The electrochemical performance of each immobilization step was studied via CV technique in the electrochemical cells containing the modified working electrode, an $\mathrm{Ag} / \mathrm{AgCl}$ as a reference electrode, and a platinum wire as counter electrode in $\mathrm{K}_{4}\left[\mathrm{Fe}\left(\mathrm{CN}_{6}\right) 0.3 \mathrm{H}_{2} \mathrm{O}\right]$ solution.

At first, the $\mathrm{WS}_{2}$ QDs were drop casted on pre-cleaned GCE. Then, AuNPs were electrochemically deposited on the $\mathrm{WS}_{2}$ QDs via CV technique. Next, the modified electrode was incubated with M13 phage solution as the biorecognition element. Finally, the unbound phages were removed by immersing the modified electrode in phosphate buffer solution (PBS, $\mathrm{pH}=7$ ) for $1 \mathrm{~min}$.

\section{Results and discussion Characterization of $\mathrm{WS}_{2}$ QDs FTIR}

The FTIR absorption peaks are illustrated in (Additional file 1: Figure S1). Based on the obtained FTIR peaks, WS ${ }_{2}$ QDs have two characteristic absorption peaks, where the first one approximately appeared at $659 \mathrm{~cm}^{-1}$, which was associated to the wolfram-sulfur (W-S) bond. The second one occurred at about $866 \mathrm{~cm}^{-1}$, which was related to the disulfide $(\mathrm{S}-\mathrm{S})$ bond. Broad peaks, which appeared at $3527 \mathrm{~cm}^{-1}(\mathrm{OH}$ bond stretching), $2933 \mathrm{~cm}^{-1}$ (methylene asymmetric stretching), $1674 \mathrm{~cm}^{-1}(\mathrm{C}=\mathrm{O}$ vibration), $1394 \mathrm{~cm}^{-1}\left(\mathrm{C}-\mathrm{NH}-\mathrm{C}\right.$ or $\mathrm{C}=\mathrm{N}-\mathrm{C}$ stretching vibration), $1257 \mathrm{~cm}^{-1}(\mathrm{C}-\mathrm{N}$ stretching) and $1097 \mathrm{~cm}^{-1}$ (C-NH-C or $\mathrm{C}-\mathrm{N}$ stretching), showed that the $\mathrm{WS}_{2}$ QDs were correctly synthesized. In addition, the good water solubility of the $\mathrm{WS}_{2}$ QDs was regarded to the presence of carboxyl and hydroxyl groups (Xu et al. 2019). 


\section{Fluorescence}

The photoluminescence (PL) activity of the synthesized $\mathrm{WS}_{2}$ QDs was characterized in 100-fold diluted samples at different excitation wavelengths (300 and $350 \mathrm{~nm}$ ). By increasing the excitation wavelengths, the PL activity increased. The fluorescence spectra are shown in (Additional file 1: Figure S2). The obtained spectra confirmed that the prepared $\mathrm{WS}_{2}$ QDS were synthesized properly. The same spectra were obtained by others (Haddad Irani-nezhad et al. 2019).

\section{SEM}

The topography of the modified electrode surface, nanoparticles' morphology, and composition of the deposited nanomaterials were successfully evaluated by SEM. In this regard, the stepwise modifications on the working electrode were prepared and their SEM images were taken. The SEM images are illustrated in Fig. 1A-C. As demonstrated in the different panels, the size of the $\mathrm{WS}_{2}$ QDs are approximately in the range of $25 \mathrm{~nm}$ and the average size of the electrodeposited AuNPs are in the range of 25-45 nm. After casting bacteriophage as biorecognition element on the modified electrode, the surface morphology was changed. Because of the small size of the phages, their unique structures weren't specified by SEM. However, through the changes in the surface characteristics, it could be concluded that the bacteriophages were desirably conjugated on the modified electrode via N-Au and S-Au bonds. Furthermore, the SEM images were validated via the Energy-Dispersive X-Ray Analysis (EDX).

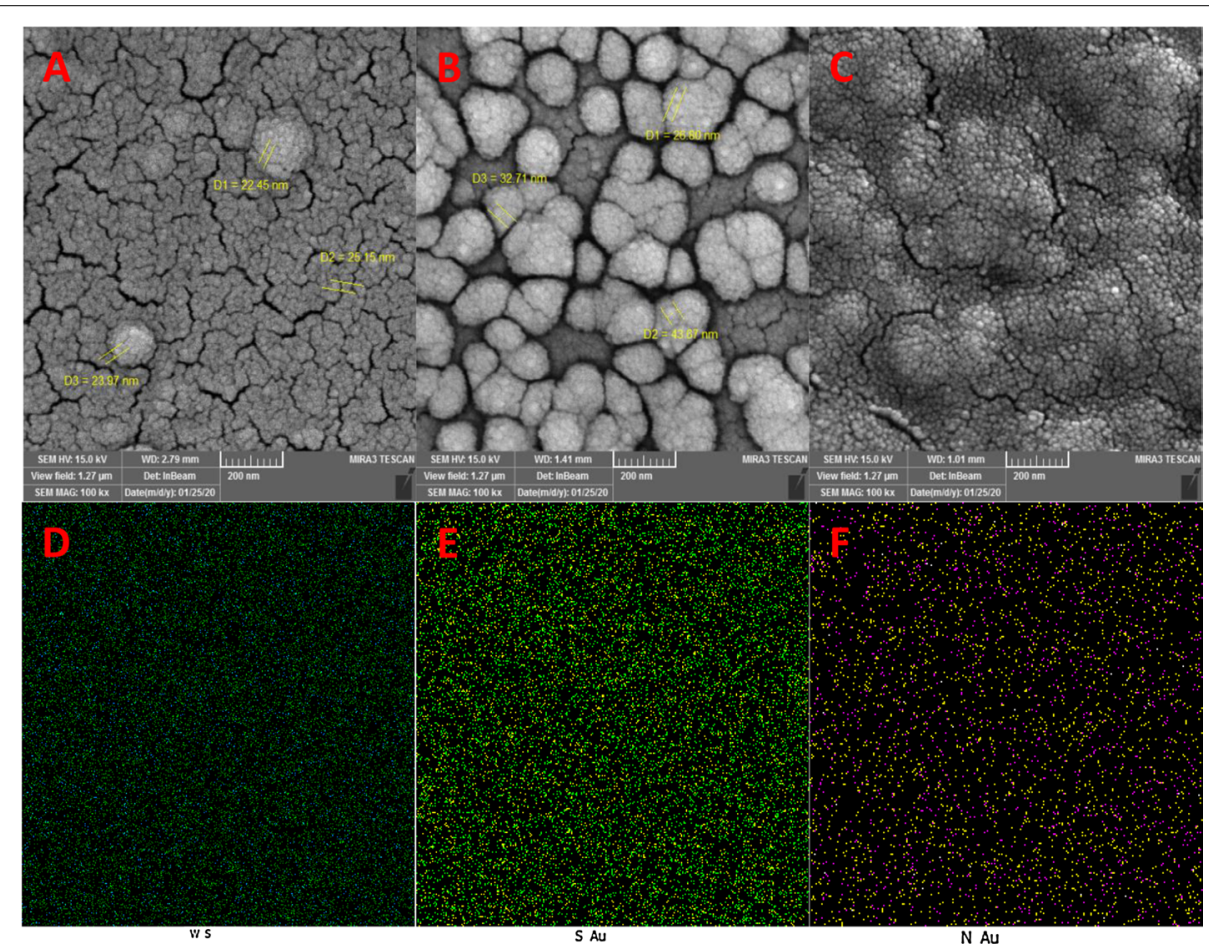

Fig. 1 SEM images of $\mathbf{A} W_{2}$ QDs; $\mathbf{B}$ AuNPs-WS 2 QDs; C c-Met-phage-AuNPs-WS 2 QDs and dot mapping images of $\mathbf{D} W$ and $S ; \mathbf{E} S$ and $A u$ and $\mathbf{F} N$ and $A u$, which were extracted from Energy-Dispersive $X$-Ray Analysis (EDX) from the same samples 
EDX

The presence of tungsten (W), sulfur $(\mathrm{S})$, gold $(\mathrm{Au})$ and carbon $(\mathrm{C})$ with $\mathrm{W}: \mathrm{S}$ ratio of 1:2 was revealed by EDX patterns of WS2 QDs, as shown in Fig. 1D, E. The presence of ' $C$ ' is due to carbonic based working electrode (GCE), while the presence of gold is mostly because of gold sputtering process during sample preparation for EDX and SEM. On top of that, the correct positioning of nanoparticles (WS2 QDs and AuNPs) and biomaterials (bacteriophage) involved in the step by step modifications was approved by EDX. The EDX results are depicted in Fig. 1F. According to the results of dot mapping, $\mathrm{W}$ and $\mathrm{S}$ are next to each other, meaning that $\mathrm{WS}_{2}$ is properly arranged. Likewise, $\mathrm{Au}$ is next to $\mathrm{S}$, which means that the gold nanoparticles are immobilized on S. Besides, from the combination of $\mathrm{N}$ and $\mathrm{Au}$, it can be concluded that the phages are mostly connected to gold through the amino groups.
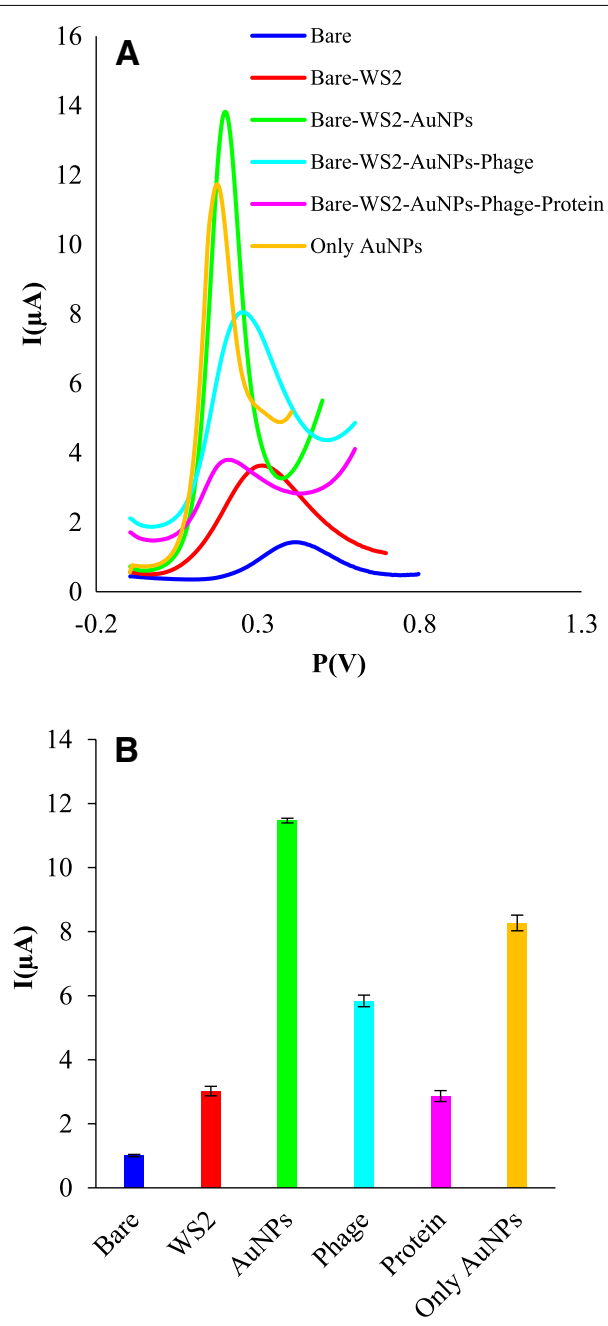

Sequential modifications

Fig. 2 A Square wave voltammograms. B The histograms of all electrode preparation steps in the standard electrochemical solution 


\section{Characterization of electrode preparation steps}

All of the electrode preparation steps were approved by square wave voltammetry (SWV) technique and are presented in Fig. 2. In this regard, at first, the bare GCE was put in the electrochemical cell containing potassium ferrocyanide (2 M) and potassium chloride $(5 \mathrm{M})$ solution. Then, $\mathrm{WS}_{2}$ QDs were immobilized on the electrode by a dropcasting method, following which the modified electrode surface was again modified via gold nanoparticles through electrosynthesis. Next, the phage solution was poured onto the modified electrode with optimized concentration.

\section{Optimizations of experimental factors Optimization of WS ${ }_{2}$ QDs thickness on GCE}

The first step of optimization is to optimize the concentration or thickness of nanomaterials on the working electrode surface. In this regard, different volumes $(1,2,3,4,5$ and $10 \mu \mathrm{L}$, as a function of concentration) of the initial prepared suspension of $\mathrm{WS}_{2}$ QDs were drop casted on the pre-cleaned GCE. Then, the $\mathrm{WS}_{2}$ QDs modified electrodes were incubated at room temperature for $1 \mathrm{~h}$. Following, the electrocatalytic activity of the $\mathrm{WS}_{2}$ QDs modified electrodes were evaluated in $\mathrm{K}_{4}\left[\mathrm{Fe}(\mathrm{CN})_{6}\right]$ as standard electrochemical solution via $\mathrm{CV}$ technique in the potential range of -0.5 to $1.0 \mathrm{~V}$ as well as scan rate of $100 \mathrm{mV}$ ( 5 cycles were recorded). The results of the voltammograms relevant to this study are shown in Fig. 3A. The average of the recorded peak heights corresponding to each volume are calculated and the histogram of average peak heights versus applied different volumes of $\mathrm{WS}_{2}$ QDs are presented in Fig. 3B. According to the obtained voltammograms and corresponding histogram, the volume of $3 \mu \mathrm{L}$ was selected as the optimal volume of $\mathrm{WS}_{2}$ QDs for further studies. Previous studies have shown that after optimizing the nanomaterial concentration or thickness on the electrode surface, any increasing of the nanomaterials' concentration or resulted thick layers could prevent redox reaction on the modified electrode or act as a semiconductor or insulating agent (Tonelli et al. 2019).

Then, the incubation temperature of the $\mathrm{WS}_{2}$ QDs on the electrode was optimized for better binding of the $\mathrm{WS}_{2}$ QDs. For this purpose, the modified electrodes were studied at different temperatures of $37{ }^{\circ} \mathrm{C}$, Room Temperature (RT), and $4{ }^{\circ} \mathrm{C}$ for $1 \mathrm{~h}$ as constant incubation time. To investigate this step, the $\mathrm{CV}$ technique was applied, such as the previous optimization. The obtained voltammograms are shown in (Additional file 1: Figure S3A). In addition, the average of 5 replicates of peak heights are calculated and the related histogram is depicted in (Additional file 1: Figure S3B). Based on the obtained voltammogram and linked histogram, the temperature of $37{ }^{\circ} \mathrm{C}$ was selected as the optimum temperature for further studies.

Finally, the incubation time of the $\mathrm{WS}_{2}$ QDs on the working electrode was optimized. For this purpose, the prepared electrodes were incubated at $37^{\circ} \mathrm{C}$ for $30,60,90,120$, and $140 \mathrm{~min}$ as different incubation timepoints. Again, the CV technique, such as previous optimizations, was applied for the evaluation of different incubation times. The recorded voltammograms and related histogram relevant to this study are shown in (Additional file 1: Figure S4). According to the obtained voltammograms and corresponding histogram, $60 \mathrm{~min}$ was determined as the optimal incubation time for further studies. 

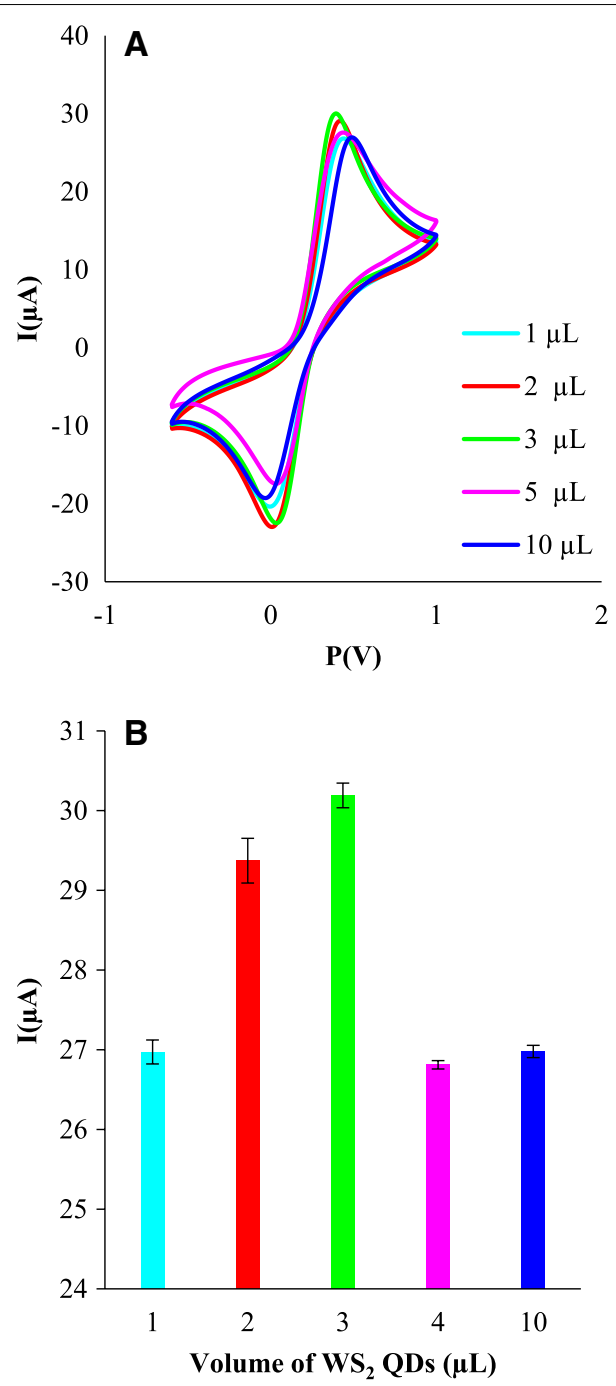

Fig. 3 A Cyclic voltammograms B The histograms of WS 2 QDs concentration at different amounts $(1,2,3,4$ and $10 \mu \mathrm{L}$ ) from the same source sample

It was observed after 60 min of incubation that by increasing the incubation time, the redox peak currents did not change significantly.

\section{Optimization of AuNPs on the WS ${ }_{2}$ QDs modified GCE}

To increase the conductivity, stabilize the $\mathrm{WS}_{2}$ QDs, and achieve the most obtainable and stable binding of phages (as bioreceptor) on the surface of the modified electrode, we used gold nanoparticles. For this purpose, a solution of $\mathrm{KCl}$ at a concentration of $0.1 \mathrm{M}$ and $\mathrm{HAuCl}_{4}$ at a concentration of $0.005 \mathrm{M}$ was prepared and transferred to the electrochemical cell. The modified electrode ( $\left.\mathrm{WS}_{2} \mathrm{QDs}-\mathrm{GCE}\right)$ was inserted into the electrochemical cell, which contained the gold solution. To optimize the thickness and morphology of the gold nanoparticles on the modified electrode, $\mathrm{CV}$ technique was performed in various cycle numbers $(10,15,20,25$ and 30) in the range of -0.5 to $0.0 \mathrm{~V}$, where the scanning rate was set in $0.05 \mathrm{~V} / \mathrm{S}$. 
To investigate the electrocatalytic properties of the modified electrodes (AuNPs-WS QDs-GCE), the CV technique was used in the range of 0-0.3 V. The recorded voltammograms relevant to this study are shown in (Additional file 1: Figure S5A). The average of peak heights of the five replicates are calculated and the associated histogram is shown in (Additional file 1: Figure S5B). According to the obtained voltammograms and linked histogram, 25 cycles was chosen as an optimal cycle number for the electropreparation of Au layer for additional studies.

\section{Optimization of Phage immobilization conditions}

After culturing and propagating the phages, $10 \mu \mathrm{L}$ of homogenous phage solution with the concentration of $10^{6}$, which is stated by the previous studies (Ertürk and Lood 2018), was dropped on the final modified electrode (AuNPs-WS 2 QDs-GCE). To optimize better binding between phage and gold, we examined the incubation temperature and time of phage binding.

To optimize the incubation temperature of phage immobilized electrodes, different temperatures of $37{ }^{\circ} \mathrm{C}$, RT, and $4{ }^{\circ} \mathrm{C}$, were examined for $1 \mathrm{~h}$. To investigate this step, $\mathrm{CV}$ techniques were applied (5 electrochemical cycles were performed). The voltammograms and histogram relevant to this study are presented in (Additional file 1: Figure S6). According to the obtained voltammograms and histogram, the temperature of $4{ }^{\circ} \mathrm{C}$ was selected as the optimum temperature for the subsequent steps. Based on the acquired results, the chemical bonding between the bioreceptor and gold nano-layer was more strong and stable at $4{ }^{\circ} \mathrm{C}$.

Next, the incubation time of phage was optimized at different timepoints of 30, 60, 120 and $180 \mathrm{~min}$ at $4{ }^{\circ} \mathrm{C}$. The corresponding voltammograms and histogram are illustrated in (Additional file 1: Figure S7). Based on the calculated results, $60 \mathrm{~min}$ was chosen as the optimal incubation time. The lowest interaction of phages occurred at 30 and $300 \mathrm{~min}$. According to the results obtained after $60 \mathrm{~min}$ of incubation, increasing the incubation time did not affect the interactions between the bioreceptor and gold nano-layer.

\section{Optimization of the target protein capturing conditions}

The last step of optimization is optimizing the target protein capturing conditions on the final modified electrode (phage-AuNPs-WS ${ }_{2}$ QDs-GCE). In this regard, $10 \mu \mathrm{L}$ of $1000 \mathrm{pg} / \mathrm{mL}$ concentration of target protein (c-Met) was immobilized on the final modified electrode, and optimization of its incubation temperature and time was performed.

Temperatures of the incubation for the final modified electrodes carrying c-Met protein were monitored at $37^{\circ} \mathrm{C}, \mathrm{RT}$, and $4{ }^{\circ} \mathrm{C}$ for $1 \mathrm{~h}$, and related voltammograms and histogram are presented in (Additional file 1: Figure S8). The incubation temperature of $37^{\circ} \mathrm{C}$ was selected as the optimum temperature. According to published articles, usually the bioconjugation between protein and phage occurs at a higher temperature as compared to phage and nanomaterial binding (Singh et al. 2009).

To optimize the incubation time of the target protein, different timepoints of 30, 60, 120 and $180 \mathrm{~min}$ at $37{ }^{\circ} \mathrm{C}$ were applied. The resulted voltammograms and histogram are presented in (Additional file 1: Figure S9). Based on the achieved results, 60 min was applied as the optimal incubation time. It is expected that over $60 \mathrm{~min}$ of incubation time, damages to the protein structure may occur. 


\section{Calibration curve}

After optimization of all experimental factors, the optimized system was used to investigate the different concentrations of target protein $(1,250,500,750$ and $1000 \mathrm{pg} / \mathrm{mL})$. To evaluate this step, the SWV technique was applied in the standard electrochemical solution in the range of -0.1 to $0.6 \mathrm{~V}$ (SWV voltammograms were repeated 3 times for each concentration). The results of SWV voltammograms and histogram corresponding to the calibration curve are shown in Fig. 4. According to the calculated results, the limit of detection of the c-Met protein as a colon cancer biomarker for the designed biosensor was $1 \mathrm{pg} / \mathrm{mL}$ as well as a linear range of $1-1000 \mathrm{pg} / \mathrm{mL}$.

\section{Stability and specificity}

To evaluate the stability of the designed biosensor, after all preparation steps (c-Metphage-AuNPs-WS 2 QDs-GCE) (protein concentration, $1 \mathrm{ng} / \mathrm{mL}$ ), the SWV was applied as same as the calibration curve condition and its voltammogram was recorded for 3 times. Then it was transferred to a refrigerator $\left(4^{\circ} \mathrm{C}\right)$ by placing the cap on the final modified electrode. Four days later, three SWV voltammograms were recorded again under the same conditions, and the results were finally compared. The results indicated
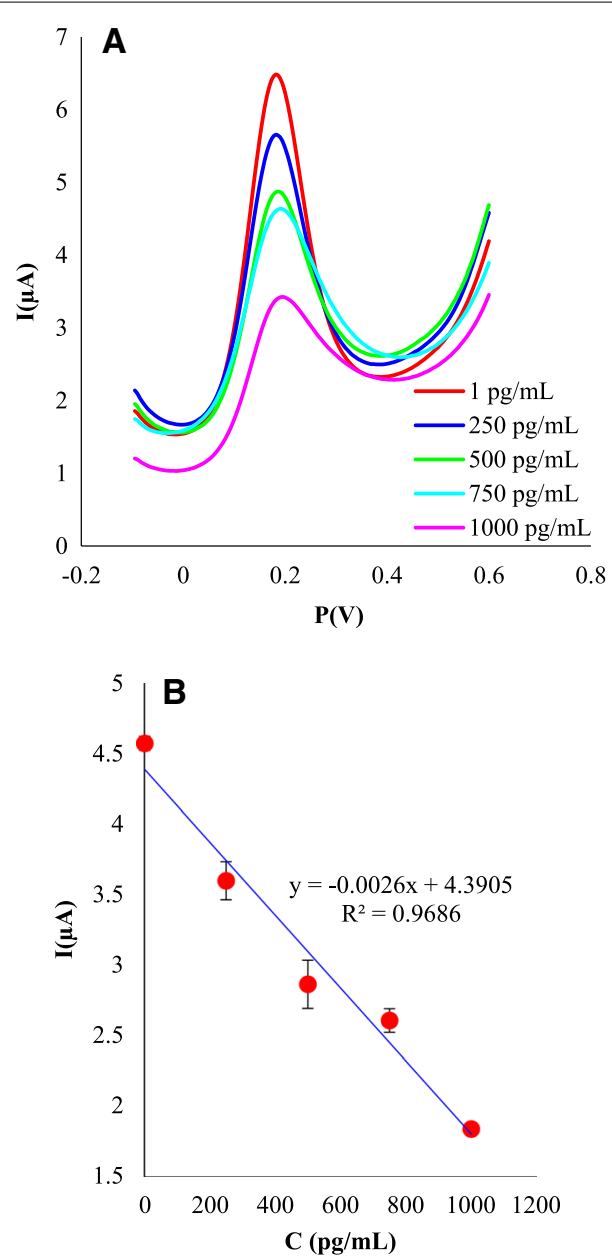

Fig. 4 A Square wave voltammograms B The histograms of calibration curve 
that the average peak height of the fifth day SWV voltammograms had increased by almost $15 \%$, as compared to the first day, proposing that by increasing the storage period some attachments related to different electrode preparation steps may be separated and detached from the GCE surface, and consequently the electrical signals increase. According to the obtained stability outcomes, the designed biosensor is sufficiently stable to be used as a commercial biosensor.

The specificity of the designed biosensor was successfully tested in the presence of two proteins (BSA, $0.05 \%$ and ROR $1,1 \mathrm{ng} / \mathrm{mL}$ concentrations). These two proteins are generally present in human serum samples. On the other hand, previous studies have shown that the BSA protein could react with gold, silver, and platinum, which reduces the sensitivity of the designed biosensors (Saptarshi et al. 2013). For this reason, both proteins (BSA and ROR1) were immobilized on the final modified electrode (c-Metphage-AuNPs-WS ${ }_{2}$ QDs-GCE) in the presence of $1 \mathrm{ng} / \mathrm{mL}$ of the target protein and were incubated at room temperature for $1 \mathrm{~h}$. Then, the SWV voltammograms were recorded as same as the calibration curve conditions. The resulted voltammograms and histograms for BSA and ROR1 are presented in Fig. 5.

\section{Repeatability}

To evaluate the repeatability of the developed biosensor (in the presence of $1 \mathrm{ng} / \mathrm{mL}$ of protein), the average peak height of the 10 replicates was calculated. Based on the recorded electrical signals, the desirable relative standard deviation (RSD) was obtained as $6.37 \%$ for repeatability measurements.

\section{Reproducibility}

To investigate the reproducibility of the designed bioassay, the two concentrations of target protein were selected as 1000 and $750 \mathrm{pg} / \mathrm{mL}$. Two separated GCEs were identically modified for 1000 and $750 \mathrm{pg} / \mathrm{mL}$, individually. The corresponding SWV

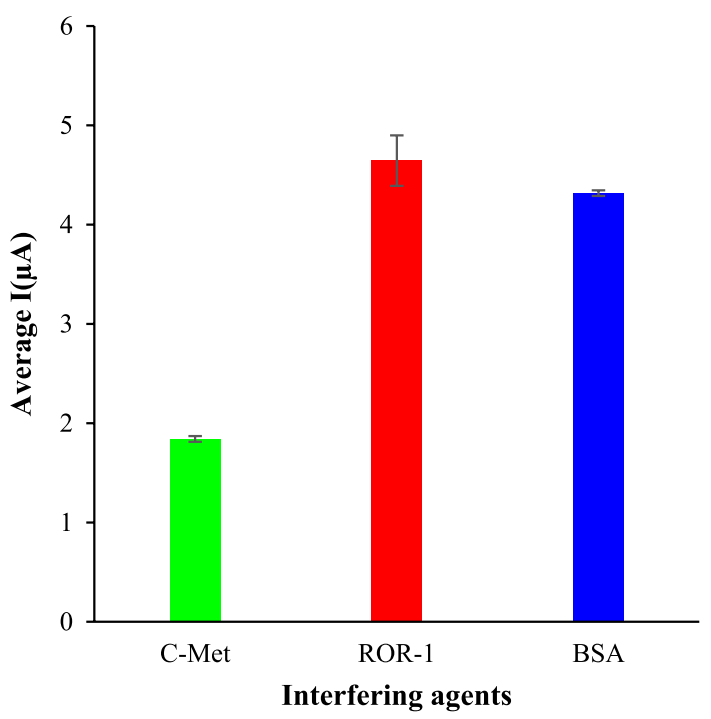

Fig. 5 Interfering agents 

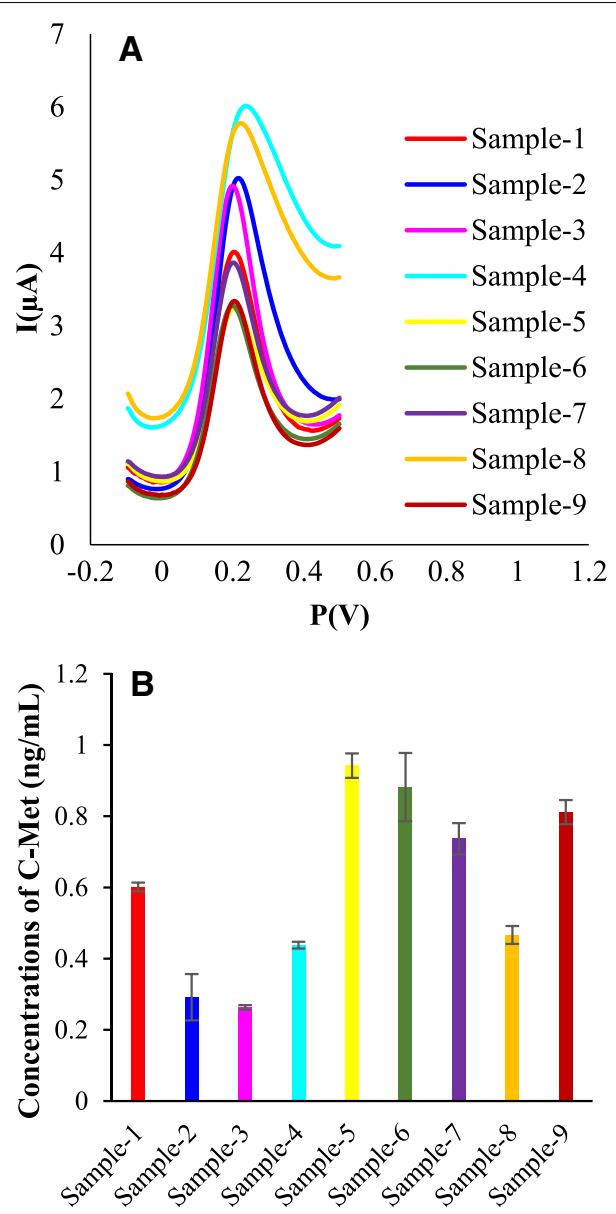

Human colon cancer serum samples

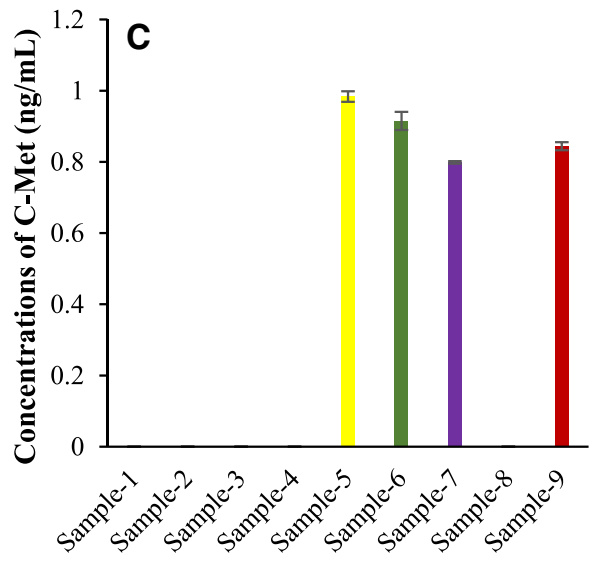

Human colon cancer serum samples

Fig. 6 Real sample analysis with designed biosensor for serum samples of different human colon cancer suffering patients at different stages. A SWV voltammograms; $\mathbf{B}$ corresponding histogram and $\mathbf{C}$ results of ELISA as a positive conventional method for the same samples 
voltammograms were recorded 3 times at the same experimental conditions. The results showed that the proposed biosensor had adequate reproducibility for clinical and commercial approaches.

\section{Real samples analysis by the developed biosensor and commercial Elisa Kit}

Lastly, the optimized bioassay was used for the quantification of c-Met protein in the serum samples of the patients with colon cancer at different stages. For this purpose, 9 patients and 1 healthy person as negative control were examined and their serum samples were collected and diluted (1:1000) with PBS. Then, $10 \mu \mathrm{L}$ of the diluted serum samples were placed on the modified electrodes (instead of target protein in the calibration curve), and their SWV voltammograms were recorded as same as the calibration curve. The results of this real sample analysis are shown in Fig. 6A. The histogram of the average peak height of the three replicates was calculated and is shown in Fig. 6B.

Also, the c-Met protein of the same samples were evaluated by the Elisa protocol (as a positive control of this study) and their results are presented in Fig. 6C.

Based on the obtained results of the reals samples, there is no difference between the healthy individual samples and the electrical signal of the modified electrode (phageAuNPs-WS ${ }_{2}$ QDs-GCE) without target protein. In other words, there is no c-Met protein in the serum sample of the healthy person to react with or be captured by the developed biosensor. Approximately the electrical signal of four patients were in the range of $250-500 \mathrm{pg}$, while five patients were in the range of 750-1000 $\mathrm{pg}$ in the obtained calibration curve. In some samples, Elisa was unable to respond (samples 1, 2, 3, 4, and 8). This is a sign of the inability of Elisa and the sensitivity of the designed biosensor.

\section{Conclusion}

In conclusion, a novel biosensor based on nanomaterials and with facile fabrication procedure was developed using non-lytic bacteriophage M13 (as bioreceptor) for measuring the c-Met protein. A great detection limit was exhibited by the sensor $(1 \mathrm{pg} / \mathrm{mL})$. This excellent limit of detection could be contributed to the high surface area of $\mathrm{WS}_{2}$ QDs and phage specificity, as well as to the effective chemical binding between M13 and the surface of well-dispersed gold nanoparticles. The specificity of the phage-based biosensor was successfully examined in the presence of ROR1 and BSA proteins, where the introduced biosensor exhibited good response with neglectable interferences. Therefore, this biosensor could be introduced as a prospective analytical tool to monitor the desired protein in real samples. Moreover, good stability is displayed by the biosensor over an extensive range of temperatures and time. In addition, high sensitivity and selectivity are observed in the reported phage-based biosensor. As a proof of concept, the constructed bioassay was effectively applied for the detection of target protein in the colon cancer suffering patients. Interestingly, the results of the developed biosensor are more precise and sensitive as compared to commercial kits. 


\section{Supplementary Information}

The online version contains supplementary material available at https://doi.org/10.1186/s12645-022-00113-2.

Additional file 1: Figure S1. WS $S_{2}$ QDs FTIR. Figure S2. WS 2 QDs fluorescence. Figure S3. A Cyclic voltammograms. B The histograms of $3 \mu \mathrm{LWS} \mathrm{SDs}_{2}$ at different incubation temperatures $\left(\mathrm{RT}, 37^{\circ} \mathrm{C}\right.$ and $\left.4^{\circ} \mathrm{C}\right)$. Figure $\mathbf{S} 4$. A Cyclic voltammograms. B The histograms of $3 \mu \mathrm{LWS} \mathrm{S}_{2}$ QDs at different incubation times $(30,60,90,120$ and $240 \mathrm{~min})$ in RT incubation temperature. Figure S5. A Cyclic voltammograms. B The histograms of AuNPs deposition process at different cycles numbers $(10,15,20,25$ and 30 cycles) in the range of -0.5 to $0 \mathrm{~V}$ and the scanning rate of $0.05 \mathrm{~V} / \mathrm{S}$. Figure S6. A Cyclic voltammograms. B The histograms of immobilization of bacteriophage at different incubation temperatures $\left(\mathrm{RT}, 37^{\circ} \mathrm{C}\right.$ and $\left.4^{\circ} \mathrm{C}\right)$. Figure S7. A Cyclic voltammograms. B The histograms of phage at different incubation times (30,60, 120, 180 and $300 \mathrm{~min})$ at $4^{\circ} \mathrm{C}$. Figure S8. A Cyclic voltammograms. B The histograms of target protein incubation temperature at RT, $37^{\circ} \mathrm{C}$ and $4^{\circ} \mathrm{C}$. Figure S9. A Cyclic voltammograms. B The histograms of incubation time of protein at $30,60,120$ and $180 \mathrm{~min}$ in $37^{\circ} \mathrm{C}$.

\section{Acknowledgements}

This work was supported by the Stem Cell Research Center (SCRC), Tabriz University of Medical Sciences, Tabriz, Iran (Grant Number: 60976).

\section{Authors' contributions}

RP was contributed in all experimental analysis and preparing of first draft. MY was the supervised the study and assisted ELISA data interpretations. MHI-n and AK were helped in synthesis and characterization of the nanomaterials. LA-M, MM and FJ-N were participated in preparation of phage library and culture. BY, HSK, MH-F were contributed in data interpretations. AS, AK, FC-K and RA were assisted in experimental analysis. BK was supervised the study and participated in idea, development of the method, validation of data and editing. M-RR was helped in research design, data analysis and method development. All authors read and approved the final manuscript.

Funding

Tabriz University of Medical Sciences, Tabriz, Iran (Grant Number: 60976).

Availability of data and materials

Not applicable.

\section{Declarations}

Ethics approval and consent to participate

All phases of this study were approved by National Committee for Ethics in Biomedical Research (IR.TBZMED.VCR. REC.1397.286). Prior to sampling, all patients were request to fill informed consent.

\section{Consent for publication}

Not applicable.

\section{Competing interests}

The authors declare no competing interest.

\section{Author details}

${ }^{1}$ Student's Research Committee, Tabriz University of Medical Sciences, Tabriz, Iran. ${ }^{2}$ Stem Cell Research Center (SCRC) Tabriz University of Medical Sciences, 51664-14766 Tabriz, Iran. ${ }^{3}$ Department of Immunology, School of Medicine, Tabriz University of Medical Sciences, Tabriz, Iran. ${ }^{4}$ Research Laboratory of Advanced Water and Wastewater Treatment Processes, Department of Applied Chemistry, Faculty of Chemistry, University of Tabriz, 51666-16471 Tabriz, Iran. ${ }^{5}$ Department of Environmental Engineering, Gebze Technical University, 41400 Gebze, Turkey. ${ }^{6}$ Immunology Research Center, Tabriz University of Medical Sciences, Tabriz, Iran. ${ }^{7}$ Pharmaceutical Chemistry, Faculty of Pharmacy, Tabriz University of Medical Sciences, Tabriz, Iran. ${ }^{8}$ Department of Immunology, Faculty of Medicine, Iran University of Medical Sciences, Tehran, Iran. ${ }^{9}$ Molecular Research Center, Tabriz University of Medical Sciences, Tabriz, Iran. ${ }^{10}$ Drug Applied Research Center, Tabriz University of Medical Sciences, Tabriz, Iran. ${ }^{11}$ Department of Oncology-Pathology, Immune and Gene Therapy Lab, Cancer Center Karolinska (CCK), Karolinska University Hospital Solna and Karolinska Institute, Stockholm, Sweden.

Received: 30 September 2021 Accepted: 3 February 2022

Published online: 05 March 2022

\section{References}

Bera D, Qian L, Tseng T-K, Holloway PH (2010) Quantum dots and their multimodal applications: a review. Materials 3(4):2260-2345

Birchmeier C, Birchmeier W, Gherardi E, Woude GFV (2003) Met, metastasis, motility and more. Nat Rev Mol Cell Biol 4(12):915-925

Chiang H-C, Wang Y, Zhang Q, Levon K (2019) Optimization of the electrodeposition of gold nanoparticles for the application of highly sensitive. Label Free Biosens Biosens 9(2):50 
Ertürk G, Lood R (2018) Bacteriophages as biorecognition elements in capacitive biosensors: phage and host bacteria detection. Sens Actuators B Chem 258:535-543

Fitzgerald RC (2020) Big data is crucial to the early detection of cancer. Nat Med 26(1):19-20

Gervais L, Gel M, Allain B, Tolba M, Brovko L, Zourob M, Mandeville R, Griffiths M, Evoy S (2007) Immobilization of biotinylated bacteriophages on biosensor surfaces. Sens Actuators B Chem 125(2):615-621

Grossman S, Milos ML, Tekawa IS, Jewell NP (1989) Colonoscopic screening of persons with suspected risk factors far colon, cancer: ii. Past history of colorectal neoplasms. Gastroenterology 96(2):299-306

Gupta S, Halm EA, Rockey DC, Hammons M, Koch M, Carter E, Valdez L, Tong L, Ahn C, Kashner M (2013) Comparative effectiveness of fecal immunochemical test outreach, colonoscopy outreach, and usual care for boosting colorectal cancer screening among the underserved: a randomized clinical trial. JAMA Intern Med 173(18):1725-1732

Haddad Irani-nezhad M, Khataee A, Hassanzadeh J, Orooji Y (2019) A chemiluminescent method for the detection of $\mathrm{H}_{2} \mathrm{O}_{2}$ and glucose based on intrinsic peroxidase-like activity of WS2 quantum dots. Molecules 24(4):689

Hasanzadeh M, Solhi E, Jafari M, Mokhtarzadeh A, Soleymani J, Jouyban A, Mahboob S (2018) Ultrasensitive immunoassay of tumor protein CA 15.3 in MCF-7 breast cancer cell lysates and unprocessed human plasma using gold nanoparticles doped on the structure of mesoporous silica. Int J Biol Macromol 120:2493-2508

Isildak I, Navaeipour F, Afsharan H, Kanberoglu GS, Agir I, Ozer T, Annabi N, Totu EE, Khalilzadeh B (2020) Electrochemiluminescence methods using $\mathrm{CdS}$ quantum dots in aptamer-based thrombin biosensors: a comparative study. Microchim Acta 187(1):1-13

Jafarizad A, Taghizadehgh-Alehjougi A, Eskandani M, Hatamzadeh M, Abbasian M, Mohammad-Rezaei R, Mohammadzadeh $\mathrm{M}$, Toğar $\mathrm{B}$, Jaymand $\mathrm{M}$ (2018) PEGylated graphene oxide/ $\mathrm{Fe}_{3} \mathrm{O}_{4}$ nanocomposite: synthesis, characterization, and evaluation of its performance as de novo drug delivery nanosystem. Bio Med Mater Eng 29(2):177-190

Jalili R, Khataee A (2019) Aluminum (III) triggered aggregation-induced emission of glutathione-capped copper nanoclusters as a fluorescent probe for creatinine. Microchim Acta 186(1):29

Jaymand M (2011) Synthesis and characterization of an exfoliated modified syndiotactic polystyrene/Mg-Al-layered double-hydroxide nanocomposite. Polym J 43(2):186-193

Khaliizadeh B, Hasanzadeh M, Sanati S, Saghatforoush L, Shadjou N, Dolatabadi JEN, Sheikhzadeh P (2011) Preparation of a new electrochemical sensor based on cadmium oxide nanoparticles and application for determination of penicillamine. Int J Electrochem Sci 6:4164-4175

Khalilzadeh B, Shadjou N, Eskandani M, Charoudeh HN, Omidi Y, Rashidi M-R (2015) A reliable self-assembled peptide based electrochemical biosensor for detection of caspase 3 activity and apoptosis. RSC Adv 5(72):58316-58326

Khalilzadeh B, Shadjou N, Charoudeh HN, Rashidi M-R (2017) Recent advances in electrochemical and electrochemiluminescence based determination of the activity of caspase-3. Microchim Acta 184(10):3651-3662

Khalilzadeh B, Rashidi M, Soleimanian A, Tajalli H, Kanberoglu GS, Baradaran B, Rashidi M-R (2019) Development of a reliable microRNA based electrochemical genosensor for monitoring of miR-146a, as key regulatory agent of neurodegenerative disease. Int J Biol Macromol 134:695-703

Khataee A, Haddad Irani-Nezhad M, Hassanzadeh J (2018) Improved peroxidase mimetic activity of a mixture of WS(2) nanosheets and silver nanoclusters for chemiluminescent quantification of $\mathrm{H}(2) \mathrm{O}(2)$ and glucose. Mikrochim Acta 185(3):190. https://doi.org/10.1007/s00604-018-2727-4

Ma PC, Maulik G, Christensen J, Salgia R (2003) c-Met: structure, functions and potential for therapeutic inhibition. Cancer Metastasis Rev 22(4):309-325

Manzoori JL, Amjadi M, Soleymani J, Tamizi E, Rezamand A, Jouyban A (2012) Determination of deferiprone in urine and serum using a terbium-sensitized luminescence method. Luminescence 27(4):268-273

Massoumi B, Abbasian M, Jahanban-Esfahlan R, Mohammad-Rezaei R, Khalilzadeh B, Samadian H, Rezaei A, Derakhshankhah H, Jaymand M (2020) A novel bio-inspired conductive, biocompatible, and adhesive terpolymer based on polyaniline, polydopamine, and polylactide as scaffolding biomaterial for tissue engineering application. Int J Biol Macromol 147:1174-1184

Polyakov AY, Yadgarov L, Popovitz-Biro R, Lebedev VA, Pinkas I, Rosentsveig R, Feldman Y, Goldt AE, Goodilin EA, Tenne R (2014) Decoration of WS2 nanotubes and fullerene-like MoS2 with gold nanoparticles. J Phys Chem C 118(4):2161-2169

Pourakbari R, Shadjou N, Yousefi H, Isildak I, Yousefi M, Rashidi M-R, Khalilzadeh B (2019) Recent progress in nanomaterialbased electrochemical biosensors for pathogenic bacteria. Microchim Acta 186(12):820

Pourakbari R, Mousavishenas MH, Kamrani A, Dolati S, Abbaszadeh H, Zamani M, Yaghoubi Y, Hashemzadeh S, Ahmadi M, Hojjat-Farsangi M (2020) Identification of genes and miRNAs associated with angiogenesis, metastasis, and apoptosis in colorectal cancer. Gene Rep 18:100552

Pumera M, Loo AH (2014) Layered transition-metal dichalcogenides (MoS2 and WS2) for sensing and biosensing. TrAC Trends Anal Chem 61:49-53

Qamsari ES, Sharifzadeh Z, Bagheri S, Riazi-Rad F, Younesi V, Abolhassani M, Ghaderi SS, Baradaran B, Somi MH, Yousefi M (2017) Isolation and characterization of anti c-met single chain fragment variable (scFv) antibodies. I Immunotoxicol 14(1):23-30

Rathore S, Hussain M, Ali A, Khan A (2013) A recent survey on colon cancer detection techniques. IEEE ACM Trans Comput Biol Bioinf 10(3):545-563

Safaie Qamsari E, Safaei Ghaderi S, Zarei B, Dorostkar R, Bagheri S, Jadidi-Niaragh F, Somi MH, Yousefi M (2017) The c-Met receptor: implication for targeted therapies in colorectal cancer. Tumor Biol 39(5):1010428317699118

Saghatforoush L, Hasanzadeh M, Karim-Nezhad G, Ershad S, Shadjou N, Khalilzadeh B, Hajjizadeh M (2009) Kinetic study of the electrooxidation of mefenamic acid and indomethacin catalysed on cobalt hydroxide modified glassy carbon electrode. Bull Korean Chem Soc 30(6):1341-1348

Saptarshi SR, Duschl A, Lopata AL (2013) Interaction of nanoparticles with proteins: relation to bio-reactivity of the nanoparticle. J Nanobiotechnol 11:26. https://doi.org/10.1186/1477-3155-11-26

Singh A, Glass N, Tolba M, Brovko L, Griffiths M, Evoy S (2009) Immobilization of bacteriophages on gold surfaces for the specific capture of pathogens. Biosens Bioelectron 24(12):3645-3651 
Soleymani L, Li F (2017) Mechanistic challenges and advantages of biosensor miniaturization into the nanoscale. ACS Sensors 2(4):458-467

Soleymani J, Perez-Guaita D, Hasanzadeh M, Shadjou N, Jouyban A (2017) Materials and methods of signal enhancement for spectroscopic whole blood analysis: novel research overview. TrAC Trends Anal Chem 86:122-142

Tonelli D, Scavetta E, Gualandi I (2019) Electrochemical deposition of nanomaterials for electrochemical sensing. Sensors 19(5):1186

Wang Z, Zhang J, Guo Y, Wu X, Yang W, Xu L, Chen J, Fu F (2013) A novel electrically magnetic-controllable electrochemical biosensor for the ultra sensitive and specific detection of attomolar level oral cancer-related microRNA. Biosens Bioelectron 45:108-113

Winawer SJ, Flehinger BJ, Schottenfeld D, Miller DG (1993) Screening for colorectal cancer with fecal occult blood testing and sigmoidoscopy. JNCl 85(16):1311-1318

Xu S, Li D, Wu P (2015) One-pot, facile, and versatile synthesis of monolayer MoS2/WS2 quantum dots as bioimaging probes and efficient electrocatalysts for hydrogen evolution reaction. Adv Func Mater 25(7):1127-1136

Xu Y, Yan L, Li X, Xu H (2019) Fabrication of transition metal dichalcogenides quantum dots based on femtosecond laser ablation. Sci Rep 9(1):1-9

\section{Publisher's Note}

Springer Nature remains neutral with regard to jurisdictional claims in published maps and institutional affiliations.

- fast, convenient online submission

- thorough peer review by experienced researchers in your field

- rapid publication on acceptance

- support for research data, including large and complex data types

- gold Open Access which fosters wider collaboration and increased citations

- maximum visibility for your research: over 100M website views per year

At BMC, research is always in progress.

Learn more biomedcentral.com/submissions 